\title{
Commercial Grass Cutting cum Collecting Machine
}

\author{
Aaqib Gulzar Khan ${ }^{1}$, Adeel-ul-Haq Qurishi ${ }^{2}$, \\ ${ }_{1,2}$ (Mechanical Engineering Department, National Institute of Technology, Srinagar, India)
}

\begin{abstract}
This paper presents the functional requirements, design and manufacture of the commercial grass cutting and collecting machine. The design is one of its kind that facilitates both the cutting and collecting of the commercial grass usually more than 4 feet long. The advantage of this design is that apart from cutting the grass it facilitates the formation of bunches, without any loss of grass arising due to scattering of grass on the account of strong cutting forces, which can be collected in a proper way. Corrosion resistance, strength, durability and hardness are important parameters for material selection of blades. Hydraulic, structural, ergonomic and engineering design was done. FEM based analysis [1] was done to calculate the stresses.
\end{abstract}

Keywords: Ergonomics, Finite Element Analysis, Grass Cutting, Modeling in Solid Works, Simulation in Ansys.

\section{INTRODUCTION}

The conventional grass cutting machines that are employed for cutting the grass in the fields have the disadvantage that during the cutting of the grass the grass gets scattered around the machine due to the strong cutting forces hence requiring further labor to collect it. The new machines that collect the grass during cutting have the disadvantage that they can cut and collect only short grass not more than 8-10 inches long. Till date the long commercial grass which is usually more than 4 feet long is reaped manually like paddy using a sickle. This method is very laborious and unproductive and hence there was a need to improve the scenario. The new grass cutter is specially designed for the reaping/harvesting of the commercial grass resulting in less fatigue to workers and increasing the productivity.

\section{DESIGN FEATURES}

The design modeling of the machine was done in SOLID WORKS 2013 [2]. Figure 1 provides a 3D view of the machine. The machine consists of a reciprocating blade cutter located at the bottom of the machine. The vertical position of the blade can be adjusted depending upon the required length of the grass to be harvested. This reciprocating blade is powered by a small single cylinder gasoline engine placed in the block behind the blades. The common lawn mower engine (HONDA GK 200) is used along with an alternator assembly. The blades are made up of alloy steel to prevent corrosion, rusting and edge blunting. The engine flywheel is attached to the blades via the cam and follower mechanism that converts rotating motion of the flywheel into reciprocating motion of the blades.

The most important part is the horizontal grass collector. It is actually a horizontal plate located just above the blades that sweeps across the blades after every single rotation of wheels. This motion is controlled by the sensor that is activated after every wheel rotation, and sends a pulse to an electric motor which is connected to the horizontal plate via the rack and pinion mechanism. For every pulse, the motor moves clock wise and counter clock wise for $200 \mathrm{~ms}$, enabling the horizontal blade to move to and fro across the blades in $200 \mathrm{~ms}$. The electric current for the sensor and the motor is derived from the alternator attached to the engine kit.

Thus, when the space between the blades is completely filled with the cut grass it sweeps at a fast pace collecting the grass along with it by the help of a hinged plate (not shown in Figure 1) located at the other end. The cut grass gets trapped between the two plates forming a bunch and the hinged plate tilts over to one side thereby releasing the collected bunch of grass. The sweep motion should be very fast so that the grass gets collected before falling down and getting scattered due to gravity or cutting forces. The hinged plate returns to its original position by the spring attached to it.

Another important feature that adds to the value of the machine is the interchangeable tires. Depending upon the surrounding location different types of the tires can be attached to the machine. In swampy areas the tires with tracks (as in tanks) can be used. Due to the 4 tires attached to machine, unlike the conventional machines which have only two tires, the machine is self-centered and balanced having no unbalanced torque or load. 


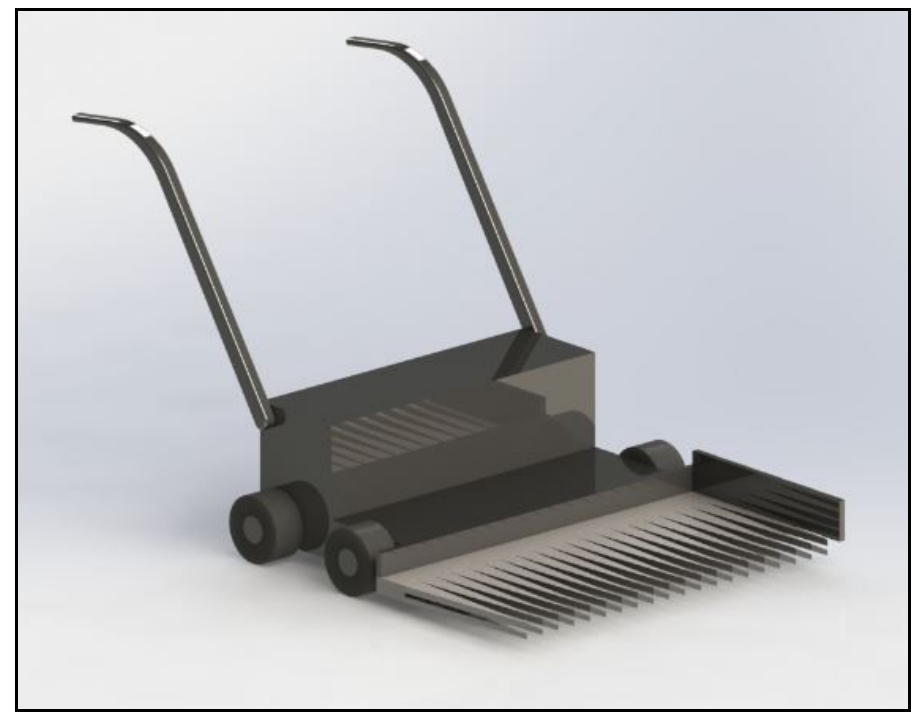

Figure 1- 3D View of the Grass Cutter.

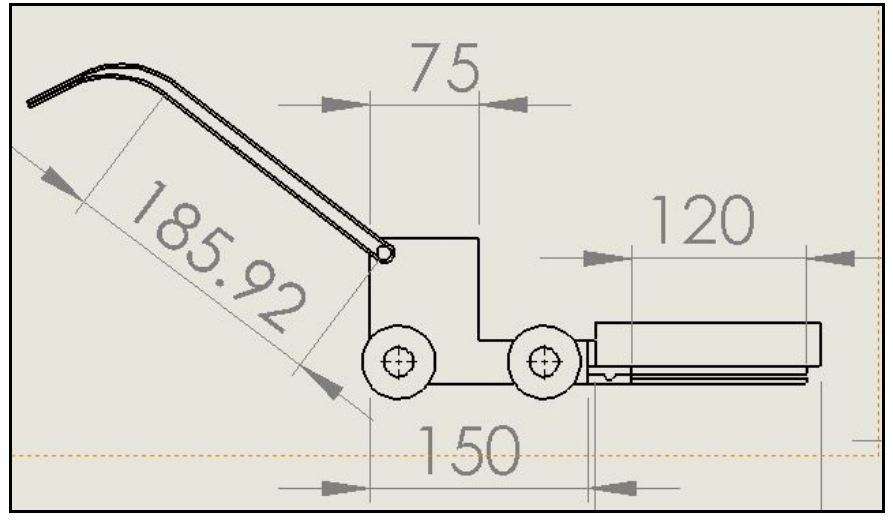

Figure 2- Front View of the Grass Cutter.

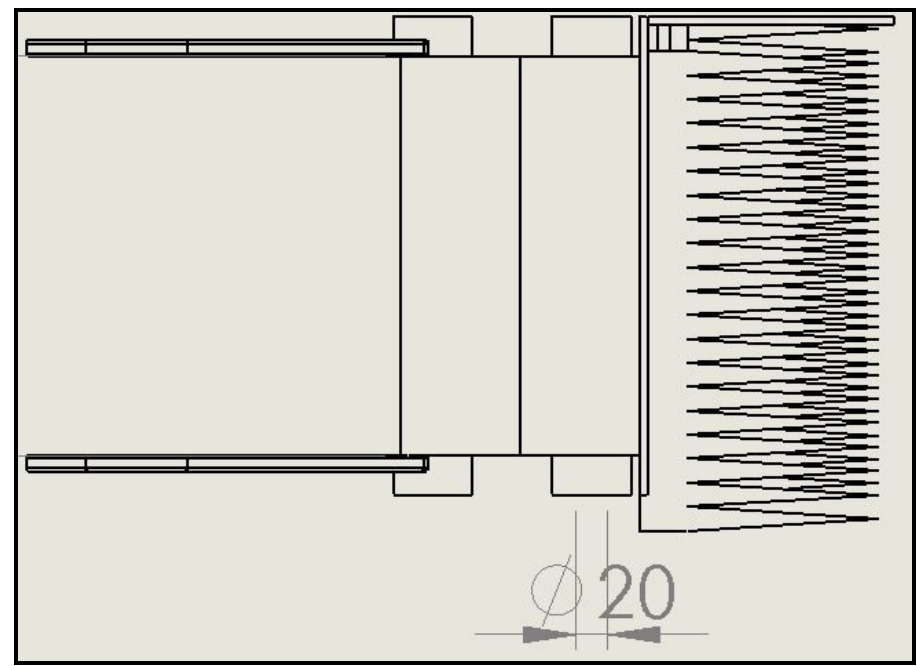

Figure 3- Top View of the Grass Cutter 


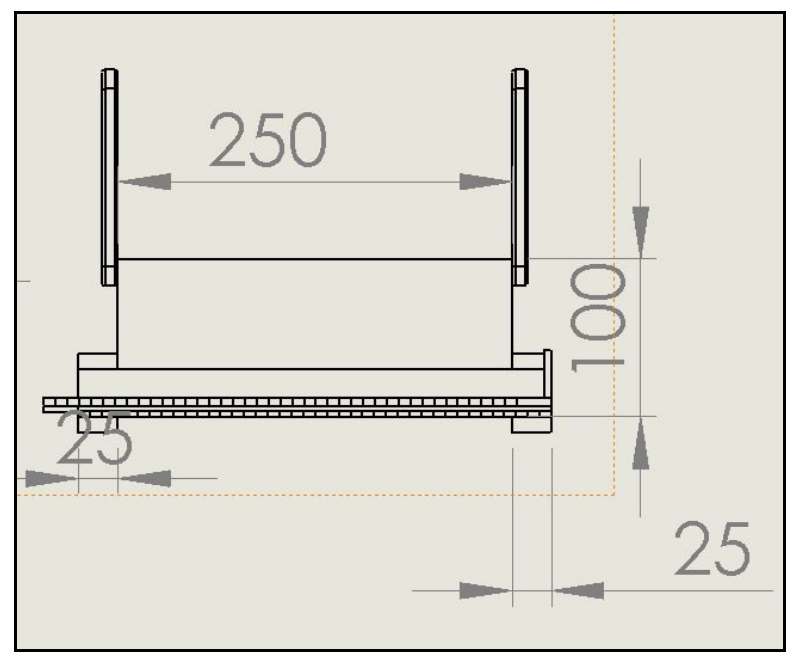

Figure 4- Side View of the Grass Cutter.

\section{Stress Analysis}

The blades were analyzed for stress failure. Tresca's yield criterion [3] was used while analyzing the model of failure due to stresses. The analysis was performed in ANSYS 14.0 Workbench [4]. The blades are made of alloy steel and its important properties are listed in Table 1.

Table 1- Properties of Alloy Steel.

\begin{tabular}{|c|c|}
\hline Property & Value \\
\hline Elastic Modulus in X & $2.1 \times 10^{11} \mathrm{~N} / \mathrm{m}^{2}$ \\
\hline Poisson's Ration in XY & 0.28 \\
\hline Shear Modulus in XY & $7.9 \times 10^{10} \mathrm{~N} / \mathrm{m}^{2}$ \\
\hline Mass Density & $7800 \mathrm{~kg} / \mathrm{m}^{3}$ \\
\hline Tensile Strength in X & $399826000 \mathrm{~N} / \mathrm{m}^{2}$ \\
\hline Yield Strength & $220594000 \mathrm{~N} / \mathrm{m}^{2}$ \\
\hline
\end{tabular}

The maximum stress attained against a fluctuating pressure of $25 \mathrm{MPa}$ and gravity was $7.36 \mathrm{MPa}$ which is very less than the yield strength. The stress intensity plot is given in Figure 5. The maximum displacement attained against a fluctuating pressure of $25 \mathrm{MPa}$ and gravity was $0.66 \mathrm{~mm}$ and the displacement plot is given in Figure 6. From the figures 5 and 6, it is clear that the design is structurally sound and therefore, we can proceed with fabrication.

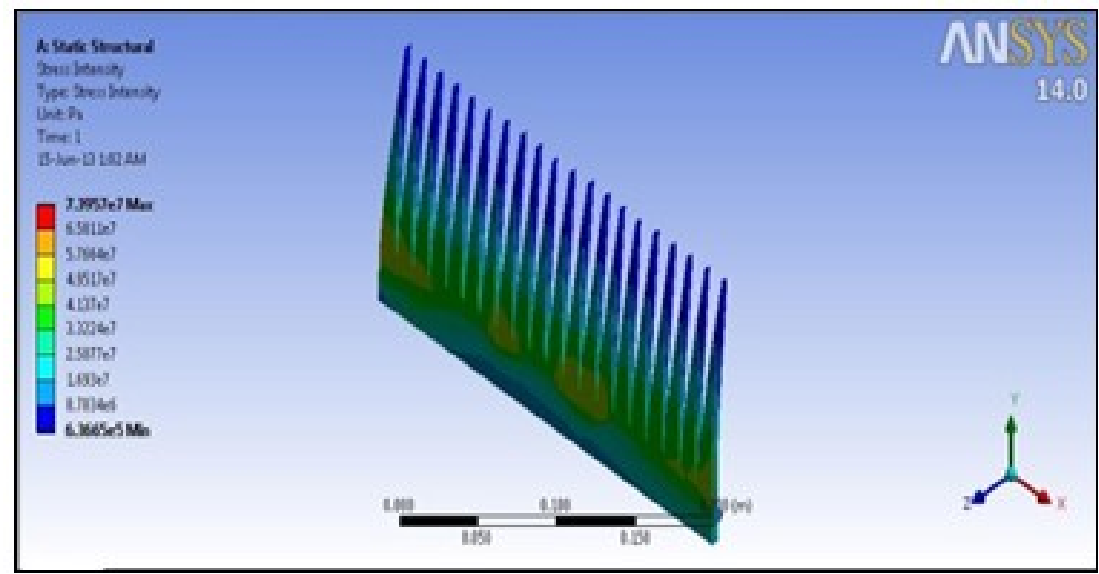

Figure 5-Stress Intensity Plot 


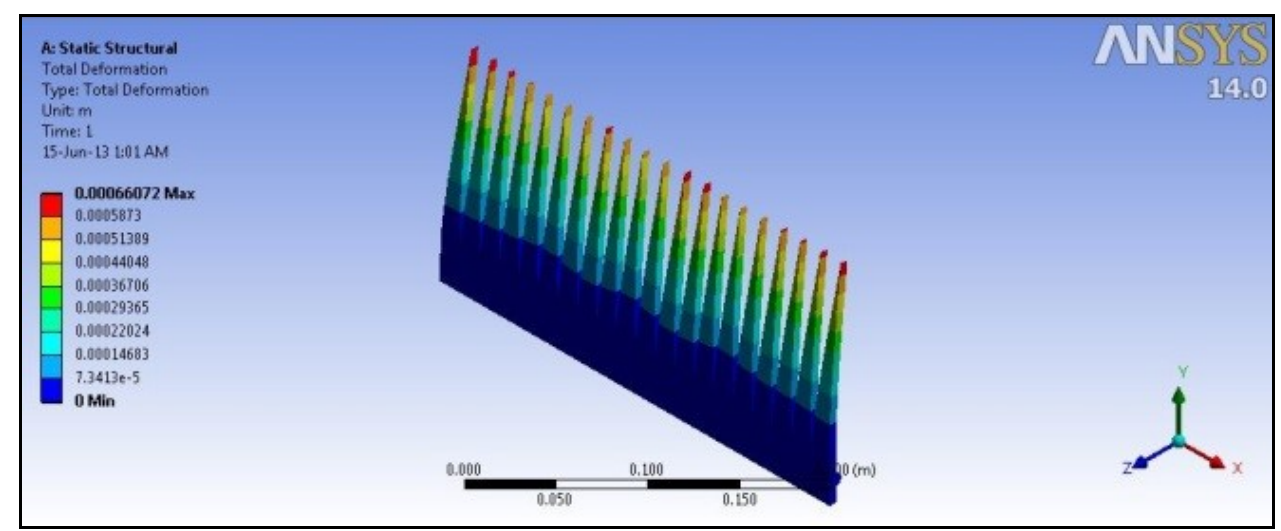

Figure 6- Displacement Plot.

\section{Conclusion}

The grass cutting machine was successfully fabricated and is under trials at the National Institute of Technology, Srinagar. The trial tests are so far in coherence with the simulated results. The machine will be launched for the commercial use shortly.

\section{Acknowledgements}

We are thankful to Mr. Saad Parvez for critically examining the design and providing various useful suggestions. We are also thankful to Mr. G M Khan for giving us the basic idea of the project and Mr. M F Wani for making fabricating material available to us.

\section{References}

[1] J N Reddy, A course on linear \& nonlinear finite element analysis (Great Clarendon Street, Oxford, Oxford University Press, 2004)

[2] Dassault Systems, Inc. (C) 2013.

[3] Egor P. Popov, Engineering mechanics of solids (Englewood Cliffs, New Jersey: Prentice-Hall, 1990).

[4] Ansys, Inc. C 